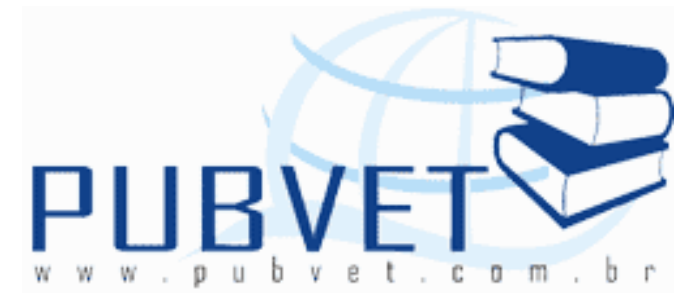

PUBVET, Publicações em Medicina Veterinária e Zootecnia.

\title{
Uso da estimulação elétrica neuromuscular em cães
}

Livia de Vargas Silva ${ }^{1}$, Graziela Barioni ${ }^{2}$, Alexandre Vinícius Pereira Silva ${ }^{3}$

Trabalho de Conclusão de Curso - Curso de Medicina Veterinária, Centro Universitário Vila Velha, Vila Velha-ES, 2010.

${ }^{1}$ Médica Veterinária Autônoma.

2 Professora Adjunta do Departamento de Medicina Veterinária (DMVET) da Universidade Federal do Espírito Santo (UFES). graziela.barioni@terra.com.br 3 Acadêmico em Medicina Veterinária na Universidade Federal do Espírito Santo.

\section{Resumo}

O músculo estriado esquelético tem função primária de manutenção e execução dos movimentos do corpo. Quando algum dos fatores que mantém a funcionalidade e estrutura normal do tecido muscular é comprometido, ocorre uma atrofia muscular drástica e imediata, o que resulta numa perda de volume muscular e, conseqüentemente, alta redução da capacidade deste músculo em gerar força. Dentre as três principais causas que resultam em atrofia muscular, relacionadas à Medicina Veterinária, cita-se a atrofia por desnervação, por desuso e atrofia por imobilização. Os programas de fortalecimento e ganho de massa muscular são procedimentos importantes quando há necessidade de restabelecer as funções normais de um músculo, quando este apresenta força 
diminuída. A estimulação elétrica neuromuscular (EENM) está sendo utilizada em grande escala nos tratamentos que visam o aumento da força muscular, tendo como ação a estimulação elétrica dos neurônios motores, induzindo assim, uma contração muscular similar à contração voluntária fisiológica. 0 objetivo do presente trabalho é analisar através de uma revisão de literatura, os resultados de diferentes estudos e pesquisas sobre o fortalecimento, contração, e ganho de massa muscular; recrutamento de fibras e fadiga muscular, utilizando a uso da EENM em pacientes com atrofia muscular induzida.

Palavras-chave: eletroterapia, eletroestimulação, estimulação elétrica neuromuscular, fortalecimento muscular, recrutamento de fibras, atrofia muscular, fadiga muscular.

\section{Use of neuromuscular electrical stimulation in dogs}

\section{Abstract}

The skeletal muscle has the primary function of maintenance and execution of body movements. When some of the factors that keep the normal structure and function of muscle tissue are compromised, a drastic and immediate muscle atrophy occur, resulting in a loss of muscle volume and, consequently, high reduction to ability of the muscle generate force. Among the three main causes that result in muscle atrophy, related to Veterinary Medicine, cites to denervation atrophy, disuse atrophy and immobilization. Strengthening programs and gain muscle mass are important procedures when you need to restore the normal muscle functions when it has diminished strength. Neuromuscular electrical stimulation (NMES) is being used extensively in treatments aimed at muscle strength increasing, having as its electrical stimulation of motor neurons, thus inducing, muscle contraction similar to physiological voluntary contraction. The aim of this work is to analyze through a literature review, the results of different studies and research on the 
SILVA, L.V., BARIONI, G. e SILVA, A.V.P. Uso da estimulação elétrica neuromuscular em cães. PUBVET, Londrina, V. 7, N. 17, Ed. 240, Art. 1584, Setembro, 2013.

strengthening, contraction, and muscle mass; fiber recruitment and muscle fatigue using the use of NMES in patients with muscular atrophy induced.

Keywords: electrotherapy, electrical stimulation, neuromuscular electrical stimulation, muscle strengthening, fiber recruitment, muscle atrophy, muscle fatigue.

\section{Introdução}

Os efeitos benéficos da fisioterapia na recuperação de pacientes humanos já são bem conhecidos (LEVINE, MILLIS e MARCELLIN-LITTLE, 2008). Porém, esta área é a mais próspera e jovem de todas as especialidades na Medicina Veterinária (MIKAIL, 2006) e, segundo Levine, Millis e Marcellin-Little (2008), dentro da fisioterapia são indicadas várias aplicações clínicas, visando restaurar, manter e promover melhor funcionalidade e aptidão física, bem estar e qualidade de vida.

Os programas de fortalecimento e ganho de força muscular são procedimentos importantes e muito utilizados na fisioterapia. Surgiram na necessidade de restabelecer as funções normais de um músculo quando este apresenta força diminuída (NORONHA et. al., 1997; EVANGELISTA et. al., 2001). Como exemplo, um desuso prolongado decorrente de alguma lesão neurológica ou ortopédica, pode resultar em uma rápida atrofia da musculatura (KORNEGAY, 1997). Como recurso da fisioterapia, Salter, Richmond, Loeb (2003) e Pires (2004) afirmam que a eletroestimulação (EE) é a modalidade terapêutica de escolha utilizada na prevenção da atrofia muscular por desuso.

Em toda literatura consultada, verificou-se um número limitado de artigos científicos e pesquisas sobre o uso da eletroestimulação em pequenos animais que desenvolveram atrofia muscular por desuso, tendo que recorrer na maioria das vezes, a pesquisas realizadas em humanos. 


\section{Revisão de Literatura}

\subsection{Musculatura esquelética}

\subsubsection{A Unidade Motora.}

O músculo estriado está relacionado com a manutenção e execução dos movimentos do corpo (BREAZILE, 1996; CUNNINGHAM, 1999). Está em constante processo de remodelação, podendo ocorrer modificações em seu diâmetro e comprimento (BREAZILE, 1996).

Cada tipo de tecido muscular no corpo é formado por fibras musculares responsáveis por produzir contrações - e, por tecido conjuntivo que além de facilitar a tração, transporta as extensas fibras nervosas, vasos sanguíneos e linfáticos, caracterizando assim o tecido muscular (CLAIR, 1986; CORMACK, 2003). Tais fibras são classificadas, segundo Banks (1992), Breazile (1996) e Cunningham (1999), em fibras tipo I ou de contração lenta, e fibras tipo II ou de contração rápida.

As fibras do tipo I são vermelhas, de contração lenta (BREAZILE, 1996; LOW e REED, 2001), pois são altamente vascularizadas (LOW e REED, 2001). Elas relaxam e se contraem lentamente, pois são supridas por neurônio motores de pequeno diâmetro e baixa velocidade de condução do impulso. Segundo Breazile (1996), Low e Reed (2001), estas fibras possuem muitas enzimas oxidativas, e fadigam-se lentamente.

As fibras do tipo II são brancas, menos vascularizadas e de contração rápida (BREAZILE, 1996; LOW e REED, 2001). O neurônio motor que as supre tem diâmetro mais largo, são mielinizados e, portanto, possuem uma maior velocidade de condução dos impulsos elétricos (LOW e REED, 2001). 
Cunningham (1999), Bondan, Lallo (2006) e Rodrigues et. al. (2006), explicam que apesar de cada fibra sofrer inervação por apenas um neurônio, o axônio de cada neurônio motor ao atingir o músculo, ramifica-se e inerva diversas fibras musculares. O conjunto de fibras inervadas por um mesmo neurônio são coletivamente denominadas unidade motora (CLAIR, 1986; BREAZILE, 1996; KORNEGAY, 1997; LOW e REED, 2001; CORMACK, 2003), sendo que todas as fibras de cada unidade motora são predominantemente do mesmo tipo (LOW e REED, 2001).

\subsubsection{Alterações Musculares.}

A estrutura e a funcionalidade muscular esquelética são condicionadas pela atividade proprioceptiva, pela inervação motora, pela carga mecânica, pela realização de ciclos de estiramento/encurtamento e pela mobilidade das articulações. Quando algum desses fatores é comprometido, uma atrofia muscular desenvolve-se de forma imediata e drástica (KORNEGAY, 1997).

Na medicina veterinária, há três principais causas que induzem a atrofia muscular. Citam-se a atrofia por desnervação (KORNEGAY, 1997; O'NEILL et. al., 1999; MIKAIL, 2006), a atrofia por desuso (KORNEGAY, 1997; FERREIRA et. al. 2004) e, por último, a atrofia por imobilização (ST-AMAND et. al., 2001).

A atrofia muscular esquelética resulta na perda de volume muscular e na redução drástica da capacidade de gerar força (LU, HUANG e CARLSON, 1997; HORTOBAGYI et. al., 2000; HADDAD et. al., 2003; LIMA et. al., 2007) e, as maiores diminuições de massa são observadas na fase inicial (CORMACK, 2003). O aumento da fadiga muscular constitui outra das conseqüências funcionais da atrofia muscular (BISCHOFF, 1990; LIMA et. al., 2007) e, o efeito mais dramático da fatigabilidade, é explicado pela necessidade de recrutar um maior número de unidades motoras ou pela maior freqüência de 
excitação requerida num músculo atrofiado para desempenhar um dado tipo de tarefa motora (TALMADGE et. al., 2002). O mesmo autor ainda ressalta que numa situação de atrofia, uma maior utilização de ATP é necessária para suprir as novas necessidades do músculo, aumentando assim, a susceptibilidade à fadiga.

De acordo com Powers e Kavazis (2008), os músculos atrofiados estão ainda sujeitos a um grande risco de lesão a qualquer situação de emergência que requeira força muscular.

\subsection{Eletroestimulação (EE)}

Os programas de fortalecimento muscular são de suma importância nas clínicas fisioterapêuticas. Eles surgem devido à necessidade do estabelecimento das funções normais do músculo quando este apresenta uma diminuição da sua força (NORONHA et. al., 1997; LOW e REED, 2001; ROBERTO, 2006; ROBERTSON et. al., 2009).

No tratamento de disfunções neuromusculares, desuso de membros, atrofia muscular, fraqueza ou queda da resistência física, por exemplo, a EE tem como objetivo despolarizar o neurônio motor causando assim, a contração muscular (STEISS e LEVINE, 2008). Essa estimulação do neurônio motor visando a contração muscular é denominada Estimulação Elétrica Neuromuscular (EENM) (STEISS e LEVINE, 2008; SHAPIRO, 2009).

\subsection{Precauções e Contra-Indicações da EE}

Existem alguns casos em que a EE é contra indicada devido à probabilidade de resultados adversos que são suficientemente importantes para que, raramente, seja justificável o uso desta modalidade (ROBERTSON et. al., 2009). 
Citam-se na medicina veterinária, exemplos como o uso em região de abdômen de pacientes gestantes, áreas próximas a neoplasias malignas (STEISS e LEVINE, 2008; MIKAIL, 2009), seios carotídeos, gânglios cervicais, olhos, ouvidos, coração, áreas com sensação diminuída, em pacientes epilépticos, e sobre áreas com trombose ou tromboflebite (STEISS e LEVINE, 2008).

\subsection{Estimulação Elétrica Neuromuscular (EENM)}

A EENM é a aplicação de correntes elétricas externas visando a produção de contração muscular (NORONHA et. al., 1997). É uma das duas terapias elétricas de média intensidade existentes, as quais são caracterizadas por intensidades entre 1.000 e 100.000 Hertz (Hz), tendo como objetivos principais, contração, fortalecimento e resistência muscular (SANTLESTEBAN, 1993; DURIGAN et. al., 2005; DUNNING, HALLING e EHRHART, 2008), nos casos onde haja contra indicação para exercícios voluntários ou incapacidade do paciente realizar exercícios voluntários (DURIGAN et. al., 2005).

Em pacientes que apresentem desuso de membro, ou que estejam com imobilização de membros, a aplicação da EENM é recomendada por Olby, Halling e Glick (2008). Dessa forma mantemos o tônus muscular até o retorno do apoio e movimentação voluntária do membro (MIKAIL, 2006), retardando assim, o aparecimento de atrofia muscular (MIKAIL, 2006; OLBY, HALLING e GLICK, 2008).

Embora existam muitos estudos que indiquem a eficácia da EENM em produzir fortalecimento e hipertrofia muscular, ao contrário de humanos, poucos são os trabalhos experimentais ou em pequenos animais que indiquem mudanças estruturais nos músculos com o uso da EENM (NORONHA et. al., 1997; PELIZZARI, 2008). 
SILVA, L.V., BARIONI, G. e SILVA, A.V.P. Uso da estimulação elétrica neuromuscular em cães.

PUBVET, Londrina, V. 7, N. 17, Ed. 240, Art. 1584, Setembro, 2013.

Quando a EENM é aplicada com intensidade e duração de pulso suficiente para atingir o limiar da membrana celular, ocorre o Potencial de Ação (PA), que é conduzido pelo neurônio motor até suas terminações sobre todas as fibras musculares inervadas por ele (CUNNINGHAM, 1999; SCOTT, 2003; BONDAN e LALLO, 2006; RODRIGUES et. al., 2006; SHAPIRO, 2009), obtendo resposta idêntica aos potenciais iniciados por estímulos fisiológicos, ou seja, a contração muscular não ocorre pela ativação isolada de uma única fibra, mas sim, pela ativação de grupos de fibras musculares inervadas pelo motoneurônio em comum, que atuam em conjunto (DRUMMOND, CALIXTO e CARVALHO, 2008).

Segundo Shapiro (2009), quando o PA se propaga ao longo dos nervos motores, as fibras musculares inervadas por eles se despolarizam, e se contraem. Essa contração muscular eletricamente estimulada, é fisiologicamente diferente da contração voluntária em suas freqüências de ativação, na despolarização e, na ordem de recrutamento das fibras (SNYDERMACKLER et. al., 1991), sendo esta ultima a principal diferença (SHAPIRO, 2009).

A quantidade de corrente elétrica necessária para produzir um PA em um tipo específico de nervo varia, e segundo Low, Reed (2001) e Shapiro (2009), deve haver uma combinação mínima entre a intensidade da corrente, e a duração do pulso para ocorrer à despolarização do nervo.

Steiss e Levine (2008) ressaltam que a força de contração se altera a medida que aumentamos a intensidade ou a duração do pulso, pois mais fibras musculares são recrutadas e estimuladas (LIEBER e KELLY, 1991; STEISS e LEVINE, 2008). Já a freqüência do pulso se aumentada, resulta numa contração mais intensa e mais rápida, porém, deve-se ter cautela, pois produz fadiga muscular mais rapidamente (OWENS e MALONE, 1983). Uma freqüência ideal testada em humanos e camundongos, variou entre 35 e 50 pulsos por 
segundo (pps). O uso desta freqüência gerou uma resposta fisiológica ótima, reduzindo assim, a ocorrência de fadiga muscular (STEISS e LEVINE, 2008; SHAPIRO, 2009).

\subsection{Parâmetros Manipuláveis da EENM}

\subsubsection{Intensidade da Corrente.}

Determina a quantidade de força gerada em cada pulso da corrente elétrica (STEISS e LEVINE, 2008). De acordo com Owens, Malone (1983), Lieber e Kelly (1991), a intensidade a ser utilizada varia e, deve ser capaz de desencadear uma contração muscular uniforme e efetiva, porém, respeitando sempre o limite dos pacientes (OWENS e MALONE, 1983; LIEBER e KELLY, 1991; PELIZZARI et. al., 2008). Pelizzari (2008) afirma que, nos cães podemos medir o nível de tolerância através da inquietação, vocalização e demonstração de dor pelo animal e, segundo Brasileiro e Villar (2000), se a intensidade do estímulo for superior ao limite do paciente, gerará dor muscular em toda área afetada 24 horas após a aplicação da eletroestimulação.

A intensidade da corrente é ajustada de acordo com a força de contração muscular desejada (SHAPIRO, 2009). Ela pode ser diminuída ou aumentada, de acordo com a tolerância de cada animal (PELIZZARI et. al., 2008). Se aumentarmos a intensidade do pulso, alteramos também, a força de contração, pois mais fibras musculares são recrutadas (STEISS e LEVINE, 2008). Em pacientes que permitem o uso de intensidade mais elevada, nota-se resultados com mais rapidez (EVANGELISTA et. al., 2007).

Concluiu-se que, quanto maior for a intensidade utilizada, mais rápido se obtém os efeitos desejáveis, pois maior será o número de fibras motoras recrutadas, devido ao fato de estarem situadas mais profundamente nos 
tecidos, inversamente às fibras sensoriais, necessitando assim, de uma maior intensidade para alcançá-las (ROBERTO, 2006).

\subsubsection{Freqüência do Pulso.}

A freqüência de pulso, é a taxa de ciclo de oscilações por segundo. Ela é expressada em Hertz $(\mathrm{Hz})$ ou em pulsos por segundo (pps). Ela determina o tipo de resposta ou contração que a estimulação elétrica produzirá (STEISS e LEVINE, 2008).

Delitto et. al. (1988) recomendam freqüências entre 35 a 80 pps para pequenos animais. Porém, Owens, Malone (1983) e Shapiro (2009) garantem que freqüências acima de 50pps produzem sim, um bom fortalecimento muscular, porém resulta em maior fatigabilidade do músculo, e isto não é vantajoso para o animal que já possui a musculatura atrofiada ou enfraquecida. Já em freqüências menores que 30pps, cada pulso produz uma contração muscular separada, não sendo eficaz. Portanto, Steiss, Levine (2008) e Shapiro (2009), recomendam para pequenos animais, freqüências entre 35 a 50pps, pois os movimentos ocorrem mais próximos um do outro, se somam, e desta forma, produzem uma contração regular e uniforme, minimizando os riscos de ocorrência de fadiga muscular.

Deve-se ressaltar que, em uma contração muscular voluntária, a freqüência raramente ultrapassa 30pps e, portanto, além de uma sobrecarga de intensidade, o músculo poderá estar respondendo também a uma sobrecarga de freqüência. Por isso deve-se ter atenção para se evitar a ocorrência de fadiga muscular por sobrecarga de trabalho, balanceando sempre a freqüência e a intensidade da EENM (DELITTO et. al., 1988; STEISS e LEVINE, 2008; SHAPIRO, 2009). 
SILVA, L.V., BARIONI, G. e SILVA, A.V.P. Uso da estimulação elétrica neuromuscular em cães.

PUBVET, Londrina, V. 7, N. 17, Ed. 240, Art. 1584, Setembro, 2013.

\subsubsection{Preparação e Colocação dos eletrodos.}

Segundo Mikail (2006), Steiss e Levine (2008), para melhor condução da corrente, os pêlos sob a área de aplicação devem ser tricotomizados para diminuir a impedância, e a superfície limpa com álcool, para diminuir a oleosidade da pele. Além disso, é necessário uma camada de líquido, podendo ser água (LOW e REED, 2001), mas preferencialmente um gel condutor, com finalidade de eliminar o espaço de ar entre os pêlos (caso a tricotomia não seja realizada) e para que ocorra a passagem da corrente elétrica do eletrodo para o tecido (LOW e REED, 2001; MIKAIL, 2006).

Segundo Low e Reed (2001), quando a estimulação elétrica é aplicada para produzir uma contração muscular, é necessário que dois eletrodos de material condutor adequado sejam corretamente fixados à pele. O eletrodo ativo (negativo) deve ser colocado sobre ponto motor do músculo, e o eletrodo dispersivo (positivo) na extremidade do músculo a ser estimulado (RODRIGUES et. al., 2006; STEISS e LEVINE, 2008; SHAPIRO, 2009), desta forma, a corrente elétrica percorre paralelamente ao músculo, e é fechada ao atingir o eletrodo dispersivo (SHAPIRO, 2009). Os efeitos serão mais evidentes onde a intensidade da corrente for maior, ou seja, nos tecidos sob o eletrodo ativo (LOW e REED, 2001). Shapiro (2009) sugere que os dois eletrodos sejam paralelamente alinhados, permitindo assim, que a corrente elétrica viaje na direção das fibras musculares, a não ser quando não for possível o uso de ambos eletrodos no mesmo grupo muscular. Neste caso, se indica que o eletrodo ativo seja posicionado sob o músculo a ser estimulado, e o eletrodo dispersivo numa musculatura adjacente ao músculo estimulado.

De acordo com Low e Reed (2001), o ponto motor é um ponto onde conseguimos máxima contração muscular, pois fica próximo à junção do nervo motor com o músculo. Desta forma, a corrente aplicada neste ponto estimulará um grande número de fibras nervosas próximas, necessitando assim, de uma 
intensidade menor do estímulo elétrico do que se o eletrodo fosse posicionado em outro ponto do tecido. Os autores afirmam que quanto mais distante do ponto motor o eletrodo ativo for posicionado, maior será a intensidade de corrente necessária para produzir uma contração efetiva.

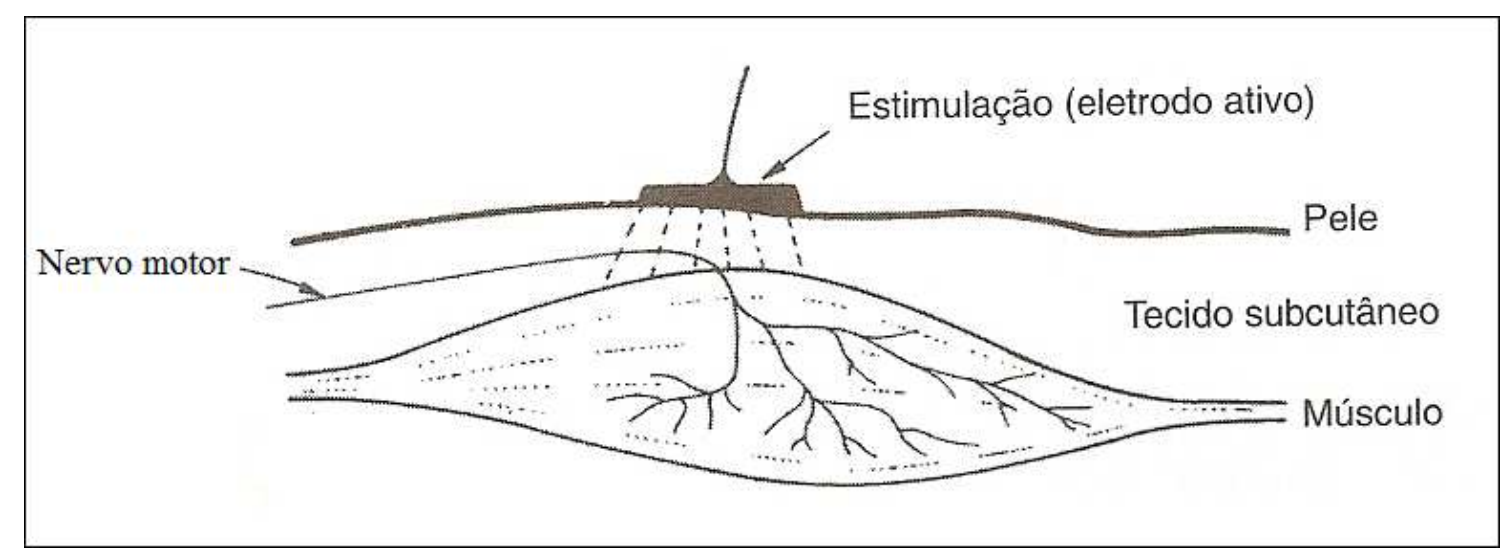

Figura 1. O Ponto motor (Fonte: LOW e REED, 2001).

Scott (2003) esclarece que, o ponto motor localiza-se próximo à junção entre o terço proximal e os dois terços distais do ventre muscular. Maldonado (2005) afirma que, com o próprio aparelho de EENM podemos localizar este ponto. Ele sugere que fixemos o eletrodo ativo na porção proximal da musculatura a ser estimulada e, o eletrodo dispersivo na região distal. O autor ressalta, porém, que não há necessidade de fazer ajustes nos parâmetros, apenas o uso de uma pequena intensidade, mínima possível para sentirmos um formigamento. O eletrodo ativo deve ser deslocado ao longo da musculatura e, quando a sensação de formigamento aumentar, significa que atingimos o ponto motor, segundo o autor.

\subsubsection{Duração ou Fase do Pulso.}

A duração do pulso caracteriza o tempo de duração de cada pulso elétrico, e é normalmente mensurada em microssegundos ( $\mu \mathrm{s})$ (ROBERTO, 2006; STEISS e LEVINE, 2008; SHAPIRO, 2009). Quando usamos a estimulação elétrica 
SILVA, L.V., BARIONI, G. e SILVA, A.V.P. Uso da estimulação elétrica neuromuscular em cães. PUBVET, Londrina, V. 7, N. 17, Ed. 240, Art. 1584, Setembro, 2013.

visando contração de um músculo inervado, a duração do pulso em humanos,

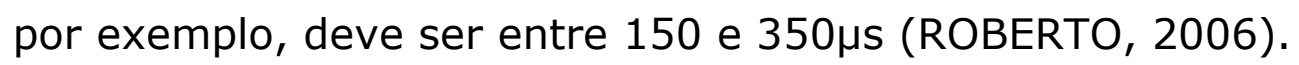

Outros estudos também feitos em humanos por Lieber e Kelly (1991), demonstraram que, a duração de pulso ideal para que ocorra uma contração uniforme e que seja ao mesmo tempo confortável para o paciente, girou em torno de $250 \mu \mathrm{s}$. Eles afirmam que pulsos menores são pouco eficazes, pois não produzem contrações uniformes e, pulsos com maior duração são desconfortáveis para a prática clínica.

Em toda literatura consultada, não foi observado trabalhos que mostram uma duração de pulso ideal para animais. Shapiro (2009) explica que a maioria dos aparelhos possui duração de pulso fixo, o que dificulta o estabelecimento da duração ideal para animais. Ele recomenda que quando este parâmetro é variável no aparelho de eletroestimulação, se use uma duração de pulso mais baixa em músculos pequenos e, mais longa nos grandes músculos.

\subsubsection{Tempo on:off.}

De acordo com Steiss e Levine (2008), o tempo on:off é a quantidade de tempo, mensurado em segundos (s), que o estimulador emite as correntes em relação ao tempo de descanso entre as contrações. Quando visamos a contração muscular, um tempo on:off é necessário para que o músculo se contraia e relaxe, impedindo assim, a fadiga muscular (SHAPIRO, 2009). 0 tempo de repouso deve ser inicialmente alto, para assegurar que a capacidade muscular de contração continue respondendo aos estímulos elétricos e evite a fadiga e, assim que as sessões prossigam, esse tempo de repouso pode ser diminuído e o tempo de contração aumentado (OWENS e MALONE, 1983).

Roberto (2006) afirma que um tempo on:off eficiente gira em torno de 1:5 (por exemplo, 10 segundos de sustentação e 50 segundos de repouso). Já 
SILVA, L.V., BARIONI, G. e SILVA, A.V.P. Uso da estimulação elétrica neuromuscular em cães. PUBVET, Londrina, V. 7, N. 17, Ed. 240, Art. 1584, Setembro, 2013.

Evangelista et. al. (2007), apontam que um tempo on:off de 1:1 como 09 segundos de contração e 09 segundos de repouso, também mostrou-se um protocolo eficiente para ganho de força muscular, em humanos.

Steiss e Levine (2008) afirmam que, experimentos em cães mostraram que o tempo on:off na proporção tanto de $1: 3$ quanto de 1:5, resultaram numa menor atrofia muscular, em relação ao grupo controle

Porém, deve-se verificar se as contrações se mantém volumosas e uniformes (ROBERTO, 2006). A eficiência das contrações devem ser estáveis e eficientes para que não ocorra a fadiga e o músculo se torne incompetente para realizar as contrações (ROBERTO, 2006; EVANGELISTA et. al., 2007; SHAPIRO, 2009).

\subsubsection{Tempo de Tratamento.}

O tempo de tratamento varia com base na atividade funcional a ser abordada. Geralmente não ultrapassa 20 minutos em uma única sessão, mas pode durar até menos, caso o paciente mostrar sinais de fadiga muscular (SHAPIRO, 2009). Ele afirma que, um músculo fadigado apresenta ausência de contrações, mesmo continuando a receber estímulos elétricos.

Caso a estimulação elétrica seja feita em cada grupo muscular separadamente, o tempo de estimulação de cada grupo, o tempo de tratamento deve ser reduzido pois é um estímulo mais intenso, podendo levar a uma fadiga mais rapidamente. Nestes casos, Scott (2003) e Robertson et. al. (2009) recomendam um tempo variado entre 5 e 7 minutos, dependendo do tamanho e espessura da musculatura estimulada.

Mikail (2006) recomenda para pequenos animais, um número de sessões entre duas a três vezes por semana, até que o paciente recupere a força para retornar a realizar movimentações voluntárias. Desta forma, não existe um 
SILVA, L.V., BARIONI, G. e SILVA, A.V.P. Uso da estimulação elétrica neuromuscular em cães. PUBVET, Londrina, V. 7, N. 17, Ed. 240, Art. 1584, Setembro, 2013.

período estipulado de tratamento quando a finalidade é o fortalecimento muscular.

\subsection{Efeitos Fisiológicos e Usos Terapêuticos da EENM}

De acordo com Low e Reed (2001), quando existem situações onde o exercício ativo voluntário está restrito, a estimulação elétrica pode ser utilizada de forma substituta. O uso da EENM é indicado para várias finalidades terapêuticas como mostrado a seguir.

\subsubsection{Contração Muscular e Recrutamento de Fibras.}

Durante a contração voluntária, os disparos dos neurônios motores não são sincronizados, Isso resulta em uma suave contração muscular e, obtemos um aumento gradual de força muscular à medida que mais unidades motoras vão sendo ativadas (DELITTO e SNYDER-MACKLER, 1990; SINACORE et. al., 1990; LOW e REED, 2001). As fibras musculares do tipo I são primeiramente recrutadas e só depois as do tipo II (SNYDER-MACKLER et. al., 1991; LOW e REED, 2001; STEISS e LEVINE, 2008). A contração muscular prolongada leva à fadiga, rapidamente das fibras musculares II e mais lentamente nas fibras do tipo I (LOW e REED, 2001).

A EENM recruta fibras musculares diferentemente de uma contração muscular voluntária. De acordo com Snyder-Mackler et. al. (1991), Low, Reed (2001) e Mikail (2006), com a EENM as fibras nervosas com axônios de maior diâmetro, que inervam as maiores fibras musculares de contração rápida (tipo II) são ativadas primeiro. Dessa forma, resulta em uma contração muscular inferior à contração muscular voluntária (SNYDER-MACKLER et. al., 1991; STEISS e LEVINE, 2008), pois ocorre o disparo sincronizado de todos os neurônios motores estimulados, ou seja, todas as unidades motoras inervadas pelo mesmo axônio se contraem simultaneamente, levando a uma contração 
SILVA, L.V., BARIONI, G. e SILVA, A.V.P. Uso da estimulação elétrica neuromuscular em cães.

PUBVET, Londrina, V. 7, N. 17, Ed. 240, Art. 1584, Setembro, 2013.

imediata com início rápido e muitas vezes brusco (DELITTO e SNYDERMACKLER, 1990; SINACORE et. al., 1990; LOW e REED, 2001).

Como as fibras tipo II fadigam-se e atrofiam-se mais rapidamente em relação ao tipo I (LOW e REED, 2001; SHAPIRO, 2009), as contrações estimuladas eletricamente podem ser mais eficazes especificamente no fortalecimento destas fibras enfraquecidas, lembrando sempre que deve ser dado um tempo de descanso entre as contrações (BONDAN e LALLO, 2006; SHAPIRO, 2009).

\subsubsection{Fortalecimento Muscular.}

Segundo Delitto e Snyder-Mackler (1990) EENM estimula preferencialmente as fibras musculares tipo II. A ativação seletiva das fibras tipo II foi comprovada por Noronha et. al., (1997), que realizaram um experimento em ratos, utilizando freqüência de 50pps, tempo on:off de $1: 1$, com 10 s de contração para 10s de repouso, e intensidade máxima que cada animal pôde suportar. 0 protocolo foi repetido 3 vezes por semana. Dez dias após a última eletroestimulação, a análise muscular demonstrou uma média de $92 \%$ de predomínio de fibras musculares tipo II.

a) Músculo Normal:

Low e Reed (2001) afirmam que inúmeros estudos em humanos mostraram que, a EENM isolada ou associada a atividades voluntárias em músculos normais, leva a ganhos de força similares ou em alguns poucos casos, até maiores do que quando o exercício voluntário é realizado sozinho.

b) Músculos Enfraquecidos:

Já em músculos enfraquecidos, tem sido relatado ganhos bastante significativos associados à melhora da função muscular com o uso da EENM. 
Low e Reed (2001) demonstram que em um estudo feito com humanos revelou que durante um período de seis semanas, grupos de pacientes com atrofia do músculo quadríceps recebendo EENM uma hora por dia, tiveram uma média de $17 \%$ de melhora da atrofia muscular em relação aos grupos não tratados. Neste caso, o protocolo estabelecido foi com a intensidade máxima que cada paciente pôde tolerar, freqüência de 30pps, duração do pulso de 2 segundos e proporção do tempo on:off de 1:4. O mesmo autor concluiu que a eficácia varia proporcionalmente com a intensidade da corrente utilizada - correntes mais altas dão melhor resultado. Além disso, quanto maior a atrofia muscular inicial, mais efetivo foi o tratamento, confirmando a tese de que musculaturas normais são menos beneficiados pela técnica.

Shapiro (2009) ressalta que, pacientes com força muscular reduzida ou fraqueza muscular pós-cirurgia, nos quais existe principalmente a atrofia das fibras tipo II, o uso precoce da estimulação elétrica pode resultar em recuperação funcional mais rápida e maiores ganhos de força do que somente com o exercício voluntário, pois estes pacientes não tem capacidade de realizar contrações com a mesma intensidade que seriam realizadas se a musculatura estivesse normal.

É comprovado que, em pacientes com fraqueza pós-cirúrgica, quando mais cedo se iniciar o uso da EENM, menor será a ocorrência de atrofia, e melhor será o ganho de força da musculatura estimulada (MIKAIL, 2006; STEISS e LEVINE, 2008; SHAPIRO, 2009).

\subsubsection{Fadiga Muscular.}

A fadiga muscular causada pela contração voluntária é bastante conhecida, porém, ainda não é completamente compreendida. Segundo Low, Reed (2001) e Shapiro (2009), contrações prolongadas resultam num aumento do recrutamento de unidades motoras para que durante um exercício, a mesma 
força muscular seja mantida, a medida que ocorre a fadiga. Portanto, deve-se esperar que a EENM resulte numa fadiga relativamente rápida, já que um conjunto fixo de unidades motoras está sendo simultaneamente estimulado, com as fibras de contração rápida tipo II sendo ativadas primeiramente, gerando uma contração brusca (DELITTO e SNYDER-MACKLER, 1990; SINACORE et. al., 1990; LOW e REED, 2001).

A EE com intensidade de $2500 \mathrm{~Hz}$, modulada em 50pps, por 30 minutos, além de um ganho da força muscular, é capaz de promover aumento da perfusão vascular, o que resulta num maior aporte sanguíneo para as fibras, permitindo assim uma melhor homeostase das células musculares, aumento das reservas de glicogênio muscular, produção de ATP e, conseqüentemente, possibilitando a contração muscular e minimizando as chances de ocorrência de fadiga (CLEMENTE et. al., 1991).

\subsection{Resultados da EENM}

Poucas pesquisas indicam os efeitos qualitativos e quantitativos da estimulação elétrica em animais experimentais, que permitam uma melhor interpretação e discussão dos resultados da EENM. No entanto, sabe-se que, a EENM é muito utilizada na fisioterapia para produção de ganho de força muscular e hipertrofia de musculaturas atrofiadas (NORONHA et. al., 1997; PIRES, 2004).

Há uma controvérsia nas pesquisas em humanos que envolvem o ganho de força muscular com o uso da EENM. Isso ocorre devido aos parâmetros manipuláveis dos aparelhos que geram correntes elétricas não obedecerem a um padrão uniforme. Existem autores que utilizam diferentes freqüências em suas pesquisas, alguns utilizam correntes com baixa intensidade, enquanto outros adotam o método de alta intensidade; a duração do pulso recebe valores variados. Isso tudo gera muita divergência nas conclusões destes experimentos (BRASILEIRO e VILLAR, 2000). Apesar de todas estas 
SILVA, L.V., BARIONI, G. e SILVA, A.V.P. Uso da estimulação elétrica neuromuscular em cães. PUBVET, Londrina, V. 7, N. 17, Ed. 240, Art. 1584, Setembro, 2013.

divergências, Laughman, Youdas, Garreit (1983), Brasileiro e Villar (2000) garantem que, a EENM isolada é capaz sim, de produzir contrações, porém, inferiores àquelas geradas pela contração voluntária. Porém, em pacientes com lesões ou em recuperação pós-cirúrgicas, Steiss e Levine (2008) afirmam que a contração muscular eletricamente induzida pode ser maior do que a contração voluntária que o paciente consegue realizar, pois seus músculos enfraquecidos estão incapacitados de contrair ao máximo e gerar a força necessária para sua manutenção.

Por exemplo, um estudo feito por Laughman, Youdas e Garreit (1983), revelou que após 5 semanas de pesquisa, um grupo de indivíduos recebendo apenas exercícios cinesioterápicos teve um ganho médio de força muscular de $18 \%$, enquanto que o ganho da força em pacientes submetidos à EENM associada à cinesioterapia foi de $22 \%$. Porém, em pacientes idosos, a EENM não tem dado resultados muito satisfatórios. A idade avançada, muitas vezes associada a patologias, contribui com a diminuição do tamanho das fibras, principalmente tipo II e, tem como consequência a queda da capacidade de produção de força (LEWEK. STEVENS e SNYDER-MACKLER, 2001).

De acordo com Noronha et. al., (1997) e Roberto (2006), a EENM é a aplicação de correntes elétricas para desencadear uma contração muscular nãovoluntária. Eles afirmam que nos anos 70, atletas humanos de Montreal que associavam o uso da EENM aos exercícios de rotina conseguiam resultados de 20 a $40 \%$ a mais de força muscular do que aqueles produzidos apenas com a contração voluntária.

Pesquisas realizadas por Owens e Malone (1983) revelaram que o uso exclusivo da estimulação elétrica gera contrações que podem chegar de $60 \%$ a $87 \%$ da contração voluntária que este músculo pode gerar, utilizando 20 e 100pps, respectivamente. Porém, é importante lembrar que o grau de fadiga muscular aumenta proporcionalmente ao aumento da freqüência utilizada (LAUGHMAN, 
YOUDAS e GARREIT, 1983; OWENS e MALONE, 1983; DELITTO et. al., 1988; BRASILEIRO e VILLAR, 2000; LEWEK. STEVENS e SNYDER-MACKLER, 2001; SHAPIRO, 2009).

Lewek, Stevens e Snyder-mackler (2001) garantem que além do protocolo de uma aplicação de EE uma vez ao dia, como indicam a maioria dos autores, outro protocolo tem demonstrado ótimos resultados em pesquisas realizadas por eles, porém, também em humanos. As pesquisas demonstraram que a porcentagem de atrofia dos músculos estimulados eletricamente com freqüência de 10pps, a cada 8 horas, por 21 dias, foi de $29 \%$ enquanto os músculos não estimulados sofreram uma atrofia de $56 \%$. Porém, os autores não revelaram dados importantes utilizados nas pesquisas, como a intensidade da contração utilizada, a duração dos pulsos, e o tempo on:off.

\section{Conclusão}

Analisando as referências utilizadas para esta revisão, conlui-se que, a EENM é um importante tratamento coadjuvante às terapias que visam o fortalecimento de musculaturas enfraquecidas e/ou atrofiadas, uma vez que ativa preferencialmente as fibras musculares de contração rápida (tipo II), mostrando-se uma forma terapêutica eficaz, desde que os parâmetros utilizados sejam corretamente manipulados para se evitar a fadiga precoce durante a sua utilização.

Para que haja resultados de boa qualidade, outros recursos também devem ser utilizados, fazendo com que a eletroterapia não deva ser indicada como um recurso substituto para os tratamentos tradicionais, mas sim, um módulo fisioterapêutico adicional.

São escassos os trabalhos que utilizam estimulação elétrica em pequenos animais. Em decorrer disto, novos estudos científicos devem ser realizados 
SILVA, L.V., BARIONI, G. e SILVA, A.V.P. Uso da estimulação elétrica neuromuscular em cães. PUBVET, Londrina, V. 7, N. 17, Ed. 240, Art. 1584, Setembro, 2013.

para confirmar as vantagens da utilização da EENM na prática da medicina veterinária, permitindo que a manipulação dos parâmetros envolvidos seja direcionada para atingir os reais objetivos da terapia.

\section{Referências Bibliográficas}

BANKS, W. J. Tecido muscular. In: Histologia veterinária aplicada. 2. ed. São Paulo: Manole, 1992. cap. 13, p. 215-236.

BISCHOFF, R. Interaction between satellite cells and skeletal muscle fibers. Development Biologists, Saint Louis. v. 109, p. 943-952. 1990.

BRASILEIRO, J. S.; VILLAR, A. F. S. Comparação dos torques gerados por estimulação elétrica e contração muscular voluntária no músculo quadríceps femoral. Revista Brasileira de Fisioterapia. v. 4, n. 2, p. 75-81. 2000.

BONDAN, E. F.; LALLO, M. A.; Fisiologia da contração muscular esquelética. In: MIKAIL, S.; PEDRO, C. R. Fisioterapia veterinária. Barueri: Manole, 2006. p. 39.

BREAZILE, J. E. Fisiologia do músculo esquelético. In: SWENSON, M. J.; REECE, W. O. Fisiologia dos animais domésticos. 11 ed. Rio de Janeiro: Guanabara Koogan, 1996. p. 777-793.

CLAIR, L. E. St. Miologia Geral. In: GETTY, R. Anatomia dos animais domésticos. 5. ed. Rio de Janeiro: Guanabara Koogan, 1986. p. 38-45.

CLEMENTE, F. R.; MATULLONLS, D. H.; BARRON, K. W.; CURRIER, D. P. Effect of motor neuromuscular electrical stimulation on microvascular perfusion of stimulated rat skeletal muscle. Physical Therapy. v. 71, n. 5, p. 52-59. 1991.

CORMACK, D. H. Tecido muscular. In: Janeiro: Guanabara Koogan, 2003. cap. 10, p. 191-206.

Fundamentos da histologia. 2. ed. Rio de

CUNNINGHAM, J. G. A sinapse neuromuscular. In:

veterinária. 2 ed. Rio de Janeiro: Guanabara Koogan, 1999. cap. 4, p. 36-50.

DELITTO, A.; ROSE, S. J.; MCKOWEN, J. M.; LEHMAN, R. C.; THOMAS, A. J.; SHIVELY, R. A. Electrical stimulation versus voluntary exercise in strengthening thigh musculature after anterior cruciate ligament surgery. Physical Therapy. v. 68, n.5, p. 660-663. 1988.

DELITTO, A.; SNYDER-MACKLER, L. Two theories of muscle strength augmentation using percutaneous electrical stimulation. Physical Therapy. v.70, n. 3, p. 158-164. 1990.

DRUMMOND, A.; CALIXTO, M. N.; CARVALHO, G. A. Estudo bibliográfico sobre a influência da eletroestimulação na fadiga muscular e no recrutamento de fibras tipo II. Revista Eletrônica de Fisioterapia, Centro Universitário UNIEURO. v. 1. 2008.

DUNNING, D.; HALLING, K. B.; EHRHART, N. Reabilitação clínica. In: LEVINE, D.; MILLIS, D. L.; MARCELLIN-LITTLE, D. J.; TAYLOR, R. Reabilitação e fisioterapia na prática de pequenos animais. São Paulo: Roca, 2008. p. 181-198. 
DURIGAN, J. L. Q.; CANCELLIERO, K. M.; POLACOW, M. L. O.; SILVA, C. A. da; GUIRRO, R. R. de J. Modelos de desuso muscular e estimulação elétrica neuromuscular: aspectos pertinentes à reabilitação fisioterapêutica. Fisioterapia em Movimento, Curitiba, v. 18, n. 4, p. 53-62. 2005.

EVANGELISTA, A. R.; GRAVINA, G. de A.; BORGES, F. dos S.; VILADIR JUNIOR, N. P. Adaptação das características fisiológicas da fibra muscular por meio da eletroestimulação. Fisioterapia Brasil. v. 4, n. 5, p. 326-334. 2007.

FERREIRA, R.; NEUPARTH, M. J.; ASCENSÃO, A.; MAGALHÃES, J.; DUARTE, J.; AMADO, F. Atrofia muscular esquelética. Modelos experimentais, manifestações teciduais e fisiopatologia. Revista Portuguesa de Ciências do Desporto, Portugal. vol. 4, n. 3, p. 94-111. 2004.

HADDAD, F.; ROY, R. R.; ZHONG, H.; EDGERTON, V. R.; BALDWIN, K. M. Atrophy responses to muscle inactivity. II. Molecular markers of protein deficits. Journal of Applied Physiology. v. 95 , p. 791-802. 2003.

HORTOBAGYI, T.; DEMPSEY, L.; FRASER, D.; ZHENG, D.; HAMILTON, G.; LAMBERT, J.; DOHM, L.; Changes in muscle strength, muscle fibre size and myofibrillar gene expression after immobilization and retraining in humans. The Journal of Physiology. v. 524, p. 293-304. 2000.

KORNEGAY, J. N. Distúrbios dos músculos esqueléticos. In: ETTINGER, S. J.; FELDMAN, E. C. Tratado de medicina interna veterinária: doenças do cão e do gato. 4. ed. Rio de Janeiro: Guanabara Koogan, 1997. p. 1019-1037.

LAUGHMAN, R. K.; YOUDAS, J.; GARREIT, T. R. Strength changes in the normal quadriceps femoris muscle as a result of electrical stimulation. Physical Therapy. v. 63, n. 4, p. 494499. 1983.

LEVINE, D.; MILLIS, D. L.; MARCELLIN-LITTLE, D. J. Introdução à reabilitação veterinária. In: LEVINE, D.; MILLIS, D. L.; MARCELLIN-LITTLE, D. J., TAYLOS, R. Reabilitação e fisioterapia na prática de pequenos animais. São Paulo: Roca, 2008. p. 01-08.

LEWEK, M.; STEVENS J.; SNYDER-MACKLER L. The use of electrical stimulation to increase quadriceps femoris muscle force in an elderly patient following a total knee arthroplasty. Physical Therapy. v. 81, p. 1565-1571. 2001.

LIEBER, R. L.; KELLY, M. J. Factors influencing quadriceps femoris muscle torque using transcutaneous neuromuscular electrical stimulation. Physical Therapy. v. 71, n. 10, p. 715723. 1991.

LIMA, S. C.; CAIERÃO, Q. M.; DURIGAN, J. L. Q.; SCHWARZENBECK, A.; SiLVA, C. A.; MINAMOTO, V. B.; GUIRRO, R. R. J. Curto período de imobilização provoca alterações morfométricas e mecânicas no músculo de rato. Revista Brasileira de Fisioterapia. v. 11, n. 4, p. 297-302. 2007.

LOW, J.; REED, A. Estimulação elétrica de nervos e músculos. In: explicada: princípios e prática. 3 ed. São Paulo: Manole, 2001. cap. 3, p. 57-152.

Eletroterapia

LU, D. X.; HUANG, S. K.; CARLSON, B. M. Electron microscopic study of long-term denervated rat skeletal muscle. The Anatomical Record. v. 248, p. 355-365. 1997. 
MALDONADO, D. C.; FERREIRA, M. C.; RIBEIRO, R. P. P.; GROSSO, A. F. Registros eletromiográficos para ilustrar as aulas de fisiologia neuromuscular. ConScientiae Saúde. São Paulo. v. 4, p. 79-86. 2005.

MIKAIL, S. Eletroterapia. In: MIKAIL, S.; PEDRO, C. R. Fisioterapia veterinária. Barueri: Manole, 2006. p. 98-100.

NORONHA, M. A. de; CAMARGO, L. C.; MINAMOTO, V. B.; CASTRO, C. E. dos S.; SALVINI, T. de F. O Efeito da estimulação elétrica neuromuscular no músculo tibial anterior de rato. Revista Brasileira de Fisioterapia. v. 2, n. 2, p.71-76. 1997.

OLBY, N.; HALLING, K. B.; GLICK, T. R. Reabilitação neurológica. In: LEVINE, D.; MILLIS, D. L.; MARCELLIN-LITTLE, D. J., TAYLOS, R. Reabilitação e fisioterapia na prática de pequenos animais. São Paulo: Roca, 2008. p. 175-178.

O'NEILL, D. S.; ZHENG, D.; ANDERSONW. K.; DOHM, G. L.; HOUMARD, J. A. Effect of endurance exercise on myosin heavy chain gene regulation in human skeletal muscle. The American Physiological Society. Greenville, v. 99, p. 414-419. 1999.

OWENS, J.; MALONE, T. Treatment parameters of high frequency electrical stimulation as established on the electro-stim 180. The Journal of Orthopaedic and Sports Physical Therapy. v. 4, n. 3, p. 162-168. 1983.

PELIZZARI, C.; MAZZANTI, A.; RAISERI, A. G.; LOPESI, S. T. dos A.; GRAÇAI, D. L.; SALBEGO, F. Z.; RAMOS, A. T.; FESTUGATTO, R.; BECKMANN, D. V.; CUNHA, M. M. da; SANTOS, R. P. dos; CARGNELUTTI, J. F.; TRINDADE PEREIRA, D. T.; MARTINS, T. B. Estimulação elétrica neuromuscular de média freqüência (russa) em cães com atrofia muscular induzida. Ciência Rural, Santa Maria, v. 38, n. 3, p. 736-742. 2008.

PIRES, F. P.; Análise dos efeitos de diferentes protocolos de eletroestimulação neuromuscular através da freqüência mediana. Revista Brasileira de Ciência e Movimento. Brasília, v. 12, n. 2, p. 25-28. 2004.

POWERS, S. K.; KAVAZIS, A. N. Atrofia do músculo esquelético induzida pela inatividade: uma breve revisão. Revista Portuguesa de Ciências do Desporto. v. 8, n. 2, p.299-307. 2008.

ROBERTO, A. E. Eletroestimulação: O exercício do Futuro. São Paulo: Phorte, 2006.

ROBERTSON, V.; WARD, A.; LOW, J.; REED, A. Estimulação elétrica - correntes e parâmetros. In: _. Eletroterapia explicada: princípios e prática. 4. ed. Rio de Janeiro: Elsevier, 2009. cap. 3, p. 39-78.

ROBERTSON, V.; WARD, A.; LOW, J.; REED, A. Efeitos da estimulação elétrica. In:

Eletroterapia explicada: princípios e prática. 4. ed. Rio de Janeiro: Elsevier, 2009. cap. 4, p. 79-104.

RODRIgUeS, L. A.; COSTA, M. L. G.; ARAÚJO, K. G. de; CISNELOS, L. de L. Estimulação elétrica e performance muscular. In: CISNEROS, L. de L.; SALGADO, A. H. I. Guia de Eletroterapia: Princípios biofísicos, conceitos e aplicações clínicas. Belo Horizonte: Coopmed, 2006. p. 69-74.

SALTER, A. C.; RICHMOND, F. J.; LOEB, G. E. Prevention of muscle disuse atrophy by low frequency electrical stimulation in rats. Transactions on Neural Systems and Rehabilitation Engineering. v.11, p.218-226. 2003. 
SANTLESTEBAN, A. J. Agentes físicos e dor musculoesquelética. In: GOULD, J. A. fisioterapia na ortopedia e na medicina do esporte. 2 ed. São Paulo: Manole, 1993. p. 181-186.

SCOTT, O.; Ativação de nervos sensitivos e motores. In: KITCHEN, S. Eletroterapia: Prática Baseada em Evidências. 2 ed. Barueri: Manole, 2003. p. 114-146.

SHAPIRO, S. Correntes elétricas. In: CAMERON, M. H. Agentes físicos na reabilitação: da pesquisa à prática. 3 ed. Rio de Janeiro: Elsevier, 2009. p. 207-230.

SINACORE, D. R.; DELITTO, A.; KING, D. S.; ROSE, S. J. Type II fiber activation with electrical stimulation: a preliminary report. Physical Therapy. v. 70, n. 7, p. 416-422. 1990.

SNYDER-MACKLER, L.; LADIN, Z.; SCHEPSIS, A. A.; YOUNG, J. C.; Electrical stimulation of the thigh muscles after recontruction of the anterior cruciate ligament. Journal of Bone and Joint Surgery. Boston, v. 73-A, n. 7, p. 1025-1036. 1991.

ST-AMAND, J.; OKAMURA, K.; MATSUMOTO, K.; SHIMIZU, S.; SOGAWA, Y. Characterization of control and immobilized skeletal muscle: an overview from genetic engineering. The Federation of American Societies for Experimental Biology Journal. v. 15. p. 684-692. 2001.

STEISS, J. E.; LEVINE, D.; Modalidades de agentes físicos. In: LEVINE, D.; MILLIS, D. L.; MARCELLIN-LITTLE, D. J., TAYLOS, R. Reabilitação e fisioterapia na prática de pequenos animais. São Paulo: Roca, 2008. p. 75-91. 